Revue

Revue de l'histoire des religions

de Ihistoire des religions

$1 \mid 2020$

Varia

\title{
Jean WIRTH, Petite histoire du christianisme médiéval
}

Genève, Labor et Fides, 2018

Dominique logna-Prat

\section{OpenEdition}

\section{Journals}

Édition électronique

URL : https://journals.openedition.org/rhr/10359

DOI : 10.4000/rhr.10359

ISSN : 2105-2573

Éditeur

Armand Colin

Édition imprimée

Date de publication : 1 mars 2020

Pagination : 139-140

ISBN : 978-2-200-93291-6

ISSN : 0035-1423

Référence électronique

Dominique logna-Prat, « Jean WIRTH, Petite histoire du christianisme médiéval », Revue de l'histoire des religions [En ligne], 1 | 2020, mis en ligne le 01 janvier 2021, consulté le 04 janvier 2023. URL : http:// journals.openedition.org/rhr/10359; DOI : https://doi.org/10.4000/rhr.10359

Ce document a été généré automatiquement le 4 janvier 2023

Tous droits réservés 


\title{
Jean WIRTH, Petite histoire du christianisme médiéval
}

Genève, Labor et Fides, 2018

\author{
Dominique logna-Prat
}

\section{RÉFÉRENCE}

Jean WIRTH, Petite histoire du christianisme médiéval, Genève, Labor et Fides, 2018, 195 p., $22,5 \mathrm{~cm}, 19 €$, ISBN 978-2-8309-1651-5.

1 Sous un titre dont il convient d'interroger la modestie, Jean Wirth propose une réflexion d'ensemble sur le christianisme médiéval latin. «Christianisme » et non pas "Église », car, comme l'annonce la quatrième de couverture de l'ouvrage, s' « il existe de nombreux ouvrages sur l'Église au Moyen Âge [...] il n'y a pas grand-chose à lire sur la spécificité du christianisme médiéval ». La qualification de "petite histoire » a pour fonction de justifier la raison d'être non pas d'une synthèse exhaustive, mais d'un essai, avec la part d'arbitraire de tout "essai » écrit sur un ton vif, parfois provocateur, toujours stimulant, dont la principale vertu est de venir déranger les idées reçues. Parvenu à la maturité et à la hauteur de vue qui sont les privilèges d'une carrière universitaire féconde et brillante, Jean Wirth peut, certes, se permettre ce brin de coquetterie qu'est un live au titre modeste. Mais le lecteur non informé doit savoir que l'auteur est un vieux routier. Historien de l'art reconnu pour ses travaux sur l'image médiévale, la sculpture et l'architecture gothiques, mais aussi les « écarts " grotesques que sont les "marges à drôleries " des manuscrits, Jean Wirth est, en outre, un remarquable connaisseur de la première modernité à l'âge de la Réforme, qu'il s'agisse de l'art germanique de la Renaissance à Genève, des écrits de Luther ou des problèmes de l'iconoclasme. Sa Petite histoire du christianisme médiéval paraît d'ailleurs chez Labor et Fides, une maison d'édition protestante, dans une collection («Histoire des religions ») propre à ouvrir l'histoire du christianisme aux religions au pluriel, à preuve les deux derniers titres parus en 2017 juste avant l'ouvrage de Jean Wirth : Vincent 
Gossaert, Bureaucratie et salut. Devenir un dieu en Chine, et Guy Stroumsa, Religions d'Abraham. Histoires croisées.

2 En 180 pages, auxquelles s'ajoute une solide bibliographie de référence riche de titres dans toutes les langues (spécialement de nombreux titres allemands anciens souvent négligés), l'auteur brosse un état personnel de la question suivant un découpage en huit chapitres d'importance inégale : le Livre (la Bible) ; la doctrine (péché originel, Trinité, Vierge Marie, anges, fins dernières) ; l'Église (en tant que parenté spirituelle et instance médiatrice) ; la réforme permanente (pour expliquer les adaptations du christianisme des origines aux questions sociales et politiques du Moyen Âge latin); savoir et pouvoir; l'échange avec le ciel (le chapitre de loin le plus développé, riche de nombreux développements originaux sur les objets et les modes transitionnels : croix, reliques, images, donations...) ; la réforme contre l'Église pour bien saisir le saut du christianisme vers la Réforme ; enfin, en guise d'ouverture conclusive, de stimulantes réflexions sur le lien « d'hier à aujourd'hui ».

3 Soucieux de concision, l'auteur fait des choix qu'on a beau jeu de discuter. L'essentiel de ce qui fait le christianisme médiéval y est, mais la concision est souvent synonyme d'allusion : pas sûr que le lecteur néophyte s'y retrouvera sans préalable aux chapitres de la Réforme grégorienne, de l'aristotélisme ou de l'averroïsme (pour se limiter à quelques exemples qu'il serait possible de multiplier). Plus surprenante, l'absence de considérations un tant soit peu développées sur le passage de la "chrétienté " (la communauté des disciples du Christ) à la Chrétienté (l'entité géo-politique porteuse de la théocratie pontificale à l'âge des croisades); sur la triade Sacerdotium, Imperium, Studium, qui structure le second christianisme et marque le passage, à l'âge des maîtres universitaires, à la pré-modernité politique; enfin, sur la place du christianisme médiéval face aux deux autres monothéismes, le judaïsme et l'islam, alors que la construction de la Chrétienté au Moyen Âge est en bonne partie réactive, qu'elle se fait largement contre l'autre, cet autre dont l'exclusion est fortement marquée dans l'exégèse du canon de la messe dès les années 1050 : nous, c'est-à-dire à l'exclusion des hérétiques, des juifs et des musulmans.

On trouvera tout au long des chapitres nombre d'analyses brillantes et stimulantes fécondées par un travail de première main sur une documentation originale renvoyant aux travaux antérieurs de Jean Wirth. Certaines thèses (cannibalisme eucharistique, castration du Christ) ne vont pas manquer de passer pour des provocations, ce qui serait bien dommage tant est féconde la distance critique qui les fonde - la distance qu'offrent l'histoire des religions et les apports des sciences sociales, spécialement l'anthropologie et les sciences psychologiques. Une pareille hauteur de vue critique mérite d'être jugée à l'aune de ce que Jean Wirth propose, et qui tient en deux options essentielles. La première est d'offrir une réflexion contextualisée sur le christianisme médiéval ; "contextualisée " au sens d'une prise en considération des déterminations sociales, spécialement des jeux de pouvoir et de domination constitutifs du féodalisme - une option qui rapproche ce "petit " livre de la grande et forte synthèse offerte par Jérôme Baschet dans La civilisation féodale (deuxième édition, Paris, Champ-Flammarion, 2004). Le second choix essentiel que fait Jean Wirth est de proposer une réflexion d'ensemble sur les rapports «d'hier à aujourd'hui ». Pourquoi le Moyen Âge ? En quoi peut-on parler d'un christianisme médiéval? En quoi ce christianisme du passé entretient-il un rapport avec le christianisme contemporain ? Réponse : tout a changé, et rien n'a changé. "Tout a changé », à la mesure du tournant copernicien que 
représente la modernité ; " rien n'a changé », non pas dans un vain raidissement sur les acquis de la Tradition défendus par un certain catholicisme des $\mathrm{XIX}^{\mathrm{e}}$ et $\mathrm{XX}^{\mathrm{e}}$ siècles (on lira à ce propos avec intérêt les passages consacrés aux œuvres de deux théologiens catholiques contemporains : Bertrand de Margerie, sur la Trinité, et Henri de Lubac, sur les rapports nature/surnature), mais du fait des rémanences médiévales de notre modernité.

\section{AUTEURS}

\section{DOMINIQUE IOGNA-PRAT}

École des hautes études en sciences sociales, Paris. 